João Pessoa, v. 7, n. 1, p. 39-57, jan./abr. 2019. ISSN 2318-1001

DOI: 10.22478/ufpb.2318-1001.0v0n0.35534

Disponível em: http://periodicos.ufpb.br/ojs2/index.php/recfin

\title{
CONTINGÊNCIAS PASSIVAS E TEORIA DOS PROSPECTOS: ANÁLISE DOS EFEITOS EM INDICADORES FINANCEIROS DE EMPRESAS DE CONSTRUÇÃO CIVIL E CONSTRUÇÃO PESADA ${ }^{1}$
}

CONTINGENT LIABILITIES AND PROSPECT THEORY: ANALYSIS OF THE FINANCIAL IN-
DEXES OF CIVIL CONSTRUCTION AND HEAVY-DUTY CONSTRUCTION COMPANIES

Thaís Alves da Silva ${ }^{2}$

Mestre em Ciências Contábeis (Universidade Estadual de Maringá - UEM)

Doutoranda em Administração (Universidade Estadual de Maringá - UEM)

Universidade Estadual de Maringá, Departamento de Ciências Contábeis

thaisalves.cra@gmail.com

https://orcid.org/0000-0002-9050-1575

\author{
Simone Leticia Raimundini Sanches \\ Doutora em Administração (Universidade Federal do Rio Grande do Sul - UFRGS) \\ Universidade Estadual de Maringá, Departamento de Ciências Contábeis e Programa de Pós- \\ Graduação em Ciências Contábeis (PCO) \\ slraimundini@gmail.com \\ https://orcid.org/0000-0002-7363-2573

\section{Deisy Cristina Corrêa Igarashi} \\ Doutora em Engenharia de Produção (Universidade Federal de Santa Catarina - UFSC) \\ Universidade Estadual de Maringá, Departamento de Ciências Contábeis e Programa de Pós- \\ Graduação em Administração (PPA) \\ deisyigarashi@gmail.com \\ https://orcid.org/0000-0001-6603-9846
}

\section{RESUMO}

Objetivo: Analisar o efeito dos passivos contingentes nos indicadores econômico-financeiros de empresas dos segmentos de Construção Civil e Construção Pesada listadas na BM\&FBovespa da Brasil Bolsa Balcão (B3).

\footnotetext{
${ }^{1}$ Artigo recebido em: 02/08/2017. Revisado por pares em: 18/02/2018. Reformulado em: 26/04/2018. Recomendado para publicação, após a segunda rodada, em: 12/05/2018 por Luiz Felipe de Araújo Pontes Girão (Editor Geral). Publicado em: 07/11/2018. Organização responsável pelo periódico: UFPB.

2 Endereço: Av. Cristóvão Colombo, n. 5790, Campus Universitário, Bloco C23, sala 227 - Maringá-PR, 87020-900
} 
Fundamento: A Teoria dos Prospectos assume o pressuposto de que informações sobre perdas possíveis (passivos contingentes) em empresas de construção civil e construção pesada são relevantes na tomada de decisão, pois indicam exposição ao risco de perdas futuras.

Método: Análise documental das Demonstrações Contábeis Consolidadas e Padronizadas, do ano de 2016, de 21 empresas de capital aberto do segmento de construção civil e pesada, e utilização do teste de Wilcoxon e teste de McNemar para comparar os indicadores econômico-financeiros antes e após a simulação de provisionamento dos Passivos Contingentes.

Resultados: Os Passivos Contingentes divulgados em 2016 podem causar efeitos significativos nos indicadores econômico-financeiros, principalmente nos indicadores de rentabilidade; não influenciam expressivamente o número de empresas com Patrimônio Líquido Negativo; mas provocam aumento significativo no número de empresas com Prejuízo Contábil no período, corroborando a observação de que o saldo de Resultado Líquido de 2016 é sensível ao reconhecimento dos Passivos Contingentes, indicando exposição ao risco de perdas.

Contribuições: Contribui para a literatura sobre evidenciação de passivos contingentes e utilidade da informação contábil aos usuários externos no âmbito das Finanças Comportamentais. Contribui também para o estudo e uso dos indicadores financeiros na tomada de decisão a partir de informações que podem ter utilidade preditiva.

Palavras-chave: Passivos Contingentes. Setor de Construção. Indicadores Financeiros. Teoria do Prospecto. Tomada de Decisão.

\section{ABSTRACT}

Objective: The purpose of this paper was to analyze the effect of Contingent Liabilities in the economic and financial indexes of companies in the Civil Construction and Heavy-Duty Construction segments listed on B3.

Background: The Prospects Theory assumes that information on possible losses (contingent liabilities) in construction companies and heavy-duty construction are relevant in decision making, as they indicate exposure to the risk of future losses.

Method: Documentary analysis of the Consolidated and Standardized Financial Statements for 2016 of 21 public companies in the construction and heavy construction segment and use of the Wilcoxon's test and McNemar's test to compare the economic and financial indicators before and after the simulation provisions for contingent liabilities.

Results: Contingent Liabilities disclosed in 2016 may cause significant effects on economic and financial indicators, especially in profitability indicators; do not significantly influence the number of companies with Negative Shareholders' Equity; but they caused a significant increase in the number of companies with Accounting Loss in the period, corroborating the observation that the balance of Net Income for 2016 is sensitive to the recognition of Contingent Liabilities, indicating exposure to the risk of losses.

Contributions: It contributes to the literature on the disclosure of contingent liabilities and the usefulness of accounting information to external users in the field of Behavioral Finance. It also contributes to the study and use of financial indicators in decision making based on information that may have predictive utility.

Keywords: Contingent Liabilities. Construction Sector. Financial Indexes. Prospect Theory. Decision-making. 


\section{INTRODUÇÃO}

O estudo das Finanças Comportamentais emergiu como modelo de análise direcionado à contestação do paradigma tradicional de racionalidade do agente econômico (Barberis \& Thaler, 2003), defendendo a premissa de que tais agentes não detêm informações plenas sobre probabilidades de desfechos em eventos futuros, e, portanto, o processo decisório fundamenta-se essencialmente em estratégias simplificadoras, baseadas em crenças, preferências e nos limites da capacidade cognitiva do ser humano (Simon, 1955). Nesta perspectiva, assume-se que as decisões em ambientes de negócio são condicionadas por influências de aspectos psicológicos do indivíduo, que podem culminar em erros de julgamento ou vieses cognitivos (Kahneman \& Tversky, 1979); e condições de incerteza exercem influência expressiva neste processo (Zeelenberg, Dijk, Manstead \& Pligt, 2000).

Nesse sentido, fatores condicionantes de situações contingenciais podem afetar o processo decisório de investimento. Tais fatores provêm de relações de direitos do consumidor, direitos dos funcionários, interações das entidades em âmbito governamental e fiscal, mas também decorrem de aspectos sociais e ambientais. Na contabilidade, o conceito "contingência" se refere aos passivos ou ativos que não são reconhecidos pelo fato de sua existência depender do desfecho de eventos futuros que a entidade não é capaz de controlar (Martins, Iudícibus, Gelbcke \& Santos, 2013).

Alguns estudos recentes abordam esse tema. Oliveira, Benetti e Varela (2011), Caetano, Silva, Biesdorf e Leal (2010), Farias (2004), Fonteles, Nascimento, Ponte e Rebouças (2012), Oliveira (2007), e Suave, Codesso, Pinto, Vicente e Lunkes (2013) estudaram o disclosure de passivos contingentes. Curri e Velandia (2002) examinaram o controle de passivos contingentes no gerenciamento de riscos em âmbito governamental. Cohen, Darrough, Huang e Zach (2011), Ribeiro, Ribeiro e Weffort (2013) e Ribeiro (2012) focaram o uso de passivos contingentes e provisões para fins de gerenciamento de resultados. Por fim, Kennedy, Mitchell e Sefcik (1998) estudaram a divulgação de passivos contingentes ambientais considerando aspectos da teoria da decisão.

Contudo, observa-se uma lacuna entre as pesquisas mencionadas: a avaliação dos aspectos comportamentais que podem influenciar o processo decisório quando os tomadores de decisão considerarem as contingências passivas. Assim, neste estudo, tal aspecto é abordado no âmbito da Teoria do Prospecto, desenvolvida por Amos Tversky e Daniel Kahneman, segundo a qual se avalia como determinadas informações podem influenciar significativamente o processo decisório e até levar a erros de preferência (Cardoso, Riccio \& Lopes, 2008). Dessa forma, esta pesquisa contribui para os estudos de Finanças Comportamentais, ao considerar o potencial efeito das contingências passivas na tomada de decisão.

Nesta pesquisa admite-se que há setores econômicos mais suscetíveis a contingências passivas, com destaque para os segmentos de Construção Civil e de Construção Pesada quanto à incidência de processos litigiosos. Tal fato pode estar relacionado à expansão econômica que este segmento tem experimentado na última década e à própria atividade em si.

Acerca disto, Ernst \& Young Terco (2011) ressaltam que desde o período de aceleração das obras no país decorrente de programas como Minha Casa Minha Vida (PMCMV), e Programa de Aceleração do Crescimento (PAC), o chamado Boom imobiliário, tornou-se notável a preocupação com as fragilidades e contingências trabalhistas e previdenciárias na indústria da construção. Acrescenta-se, segundo o Ministério Público do Trabalho [MPT] (2014), que a inobservância das normas de segurança e saúde no trabalho por parte das empresas de construção civil e de construção pesada, ocasionou aumento significativo no número de acidentes laborais e, também, de irregularidades nas relações trabalhistas. As práticas comuns nesses setores se referem a excessos de jornada de trabalho, turnos extraordinários sem autorização, além do descuido com aspectos de segurança e bem-estar dos trabalhadores (Ernst \& Young Terco, 2011).

Esses fatos, de acordo com Ernst \& Young Terco (2011), desencadearam, no período de 2007 a 2010, aumento de $232 \%$ no número de autos de infração emitidos pelo Ministério do Trabalho e; 
aumento nos gastos públicos com reabilitação da saúde e/ou benefícios concedidos aos funcionários, e, por consequência, aumento de ações regressivas acidentárias impetradas pela Previdência Social, as quais totalizaram $\mathrm{R} \$ 200$ milhões em valores a serem ressarcidos ao órgão por empresas negligentes. Ainda, dados do Tribunal Superior do Trabalho [TST] (2014), apontam que a construção, com 61.889 ocorrências de acidentes de trabalho em 2013, ficou em segundo lugar entre os segmentos de empresas com maior registro de acidentes no setor da indústria, logo atrás das indústrias de transformação. Outro aspecto negativo para o setor de construção é o não recolhimento dos tributos durante as obras. Isto implica em as empresas deste setor não obterem as certidões e licenças de conclusão de obras, ocasionando restrições na finalização formal dos empreendimentos (Ernst \& Young Terco, 2011).

Além disso, a rentabilidade do setor caiu de 11,2\%, em 2013, para 2,3\% em 2014, passando por um cenário de crise (Amorim, 2015). Em 2015, grande parte da retração do Produto Interno Bruto (PIB) do setor esteve relacionada à perda de dinamismo, situação na qual foram eliminados cerca de 500 mil postos de trabalho nas empresas de construção. Estima-se, também, que mais da metade da mão de obra na construção civil está empregada em condições de informalidade em relação à legislação trabalhista e, considerando o momento de crise econômica, existe propensão para o agravamento dessa situação (Cataldo, 2016). Ademais, o setor encerrou o ano de 2016 com queda estimada do PIB em 5,3\% e 400 mil demissões (Castelo, 2017). Ressalta-se que "grande parte da queda do desempenho produtivo do último ano está diretamente relacionada ao enfraquecimento do setor, que se deu principalmente devido a momentos instáveis na política nacional" (Serviço Brasileiro de Apoio às Micro e Pequenas Empresas [SEBRAE], 2016, p. 5).

Apesar da recente crise econômica, as ações das construtoras auferiram ganhos acumulados de até $300 \%$ ao longo do ano de 2017, em meio à tendência de redução da Selic e expectativas por alterações nas regras de distratos. Contudo, esse contexto de valorização repentina tem levantado dúvidas aos agentes de mercado, sobretudo, por ter sido alavancada por ações de empresas que, até 2016, eram cotadas por suas mínimas históricas, e que agora lideram os ganhos do setor (Barra, 2017).

Nesse sentido, este estudo assume que é necessário considerar as evidências acerca do contencioso legal das empresas de construção, que assumem a forma de contingências passivas divulgadas nos relatórios contábeis. Sobre isto, Baraldi (2012) comenta que as empresas de construção não podem omitir informações desta natureza porque os stakeholders têm conhecimento do acirramento da legislação sobre esta atividade, em especial, a legislação trabalhista, previdenciária e fiscal, e consequentemente, das contingências às quais estão sujeitas. Nesse sentido, Mackenzie et al. (2013) acrescentam que a área mais delicada da divulgação de contingências pode ser considerada a que envolve os litígios, sendo que estes expõem a entidade a riscos substanciais de perdas.

Mediante essas evidências, pergunta-se: as contingências passivas têm efeito significativo nos indicadores econômico-financeiros, de modo que possam influenciar a tomada de decisão? Assim, o objetivo desta pesquisa foi analisar o potencial efeito nos indicadores econômico-financeiros das empresas dos segmentos de Construção Civil e Construção Pesada listadas na BM\&FBovespa da B3, em decorrência da projeção dos passivos contingentes como provisão.

Sob a perspectiva da Teoria do Prospecto avaliam-se os possíveis vieses decisórios dos usuários da informação contábil ao prospectar investimentos em empresas expostas ao risco de passivos contingentes. Esta pesquisa contribui para a literatura sobre evidenciação de passivos contingentes e utilidade da informação contábil aos usuários externos. Também contribui para o estudo e uso dos indicadores financeiros na tomada de decisão, a partir de informações que podem ter utilidade preditiva. 


\section{REVISÃO DE LITERATURA}

\subsection{Contingências Passivas Segundo o CPC 25 (R1)}

A prática de reconhecimento, mensuração e evidenciação aplicáveis ao tratamento contábil das contingências, assim como das provisões, foram determinados, inicialmente, pela Deliberação da Comissão de Valores Mobiliários [CVM] n 489/2005. Esta deliberação tornou obrigatório para as companhias de capital aberto o cumprimento das determinações do Pronunciamento NPC $\mathrm{n}^{\circ} 22$ do IBRACON, o qual estava convergindo às normas internacionais de contabilidade. Em 2009, a Deliberação CVM n 594 tornou obrigatório o atendimento ao Pronunciamento CPC 25 (R1) - Provisões, Ativos Contingentes e Passivos Contingentes, que tem correlação com a norma internacional IAS 37 - Provisions, Contingent Liabilities and Contingent Assets.

De acordo com o Comitê de Pronunciamentos Contábeis [CPC] 25 (R1) um passivo contingente pode ser definido como uma obrigação possível resultante de eventos passados e que somente terá sua existência confirmada através da ocorrência ou não de eventos futuros, incertos, não totalmente sob o controle da entidade. Também pode consistir em obrigação presente que resulta de eventos passados, mas que não pode ser reconhecida porque a saída de recursos que incorporam benefícios econômicos para sua liquidação não é considerada provável, ou o valor da obrigação não pode ser mensurada confiavelmente. Nota-se que a condição de contingência se dá por fatos passados, os quais podem gerar uma obrigação futura devido à incerteza da sua ocorrência, ou gerar uma obrigação presente cuja liquidação não é provável, e/ou a mensuração não é confiável.

Por este motivo, os passivos contingentes não são reconhecidos como passivo exigível no Balanço Patrimonial, porque a expectativa da entidade quanto à necessidade de um desembolso de recursos para liquidá-los é considerada possível. Contudo, devem ser divulgados em Notas Explicativas, exceto em casos em que a possibilidade de uma saída de recursos que incorporam benefícios econômicos para sua liquidação seja considerada remota. A divulgação desses itens deve abranger uma breve descrição da natureza do passivo contingente e, quando praticável, a estimativa do seu efeito financeiro, a indicação das incertezas relacionadas ao valor e ao momento de ocorrência de desembolsos, assim como a possibilidade de qualquer reembolso relacionado (CPC 25 (R1), 2009).

Embora os passivos contingentes sejam divulgados em Notas Explicativas, de acordo com o CPC 25 (R1) e Martins et al. (2013), sua análise deve ser periódica, para que se possa determinar se uma saída de recursos que incorporam benefícios econômicos deixou de ser considerada possível e se tornou provável. Se constatada essa mudança, deve-se reconhecer uma provisão nas demonstrações contábeis do período em que ocorrer a mudança na estimativa (CPC 25 (R1), 2009).

A provisão, por sua vez, consiste em um passivo exigível que tem prazo ou valores incertos. Em outras palavras, as provisões diferem dos passivos exigíveis em dois quesitos: (i) não há certeza quanto ao prazo e valor da obrigação e (ii) não há uma obrigação explícita com terceiros. Também diferem das apropriações por competência, os accruals, pois estes, apesar de não terem sido pagos, faturados ou acordados de modo formal com terceiros, há menor incerteza sobre o valor e o momento de desembolso se comparados às provisões (CPC 25 (R1), 2009).

Assim, as provisões, apesar de terem natureza contingente, são reconhecidas como passivo nas demonstrações contábeis porque são obrigações presentes e há uma estimativa provável que haverá uma saída de recursos para liquidar a obrigação. Desse modo, para o reconhecimento da provisão é necessário que: a entidade tenha uma obrigação presente, a qual pode ser legal ou não formalizada, mas resultante de eventos passados; seja provável que será necessário um desembolso de recursos que incorporam benefícios econômicos para liquidar a obrigação; e uma estimativa confiável do valor da obrigação possa ser feita (CPC 25 (R1), 2009).

Assim como as contingências passivas, as provisões também precisam ser reavaliadas na data de reporte das demonstrações contábeis, ajustadas para refletir a melhor estimativa do período corrente e divulgadas. Entretanto, se já não for mais considerada provável a necessidade de saída 
de recursos que incorporam benefícios econômicos futuros para liquidar a obrigação, a provisão deve ser revertida (CPC 25 (R1), 2009).

Em síntese, ao avaliar os passivos reconhecidos e/ou divulgados, um aspecto que retrata a essência econômica é a determinação sobre a existência, ou não, de uma obrigação presente na data do Balanço Patrimonial. Para isso, é necessário que se considere toda a evidência disponível, incluindo a opinião de peritos e evidências adicionais objetivas proporcionadas por eventos do período subsequente. Então, de posse das evidências, se a entidade constatar que é mais provável a existência de uma obrigação presente na data do reporte do Balanço Patrimonial (do que sua não existência), esta deve reconhecer uma provisão. Caso constate que é mais provável a não existência de uma obrigação presente nessa data, a entidade deve divulgar um passivo contingente. E, se a entidade constatar que é remota a existência da obrigação presente, não é necessária a divulgação do passivo contingente (CPC 25 (R1), 2009).

Nesse sentido, Baraldi (2012) considera que um passivo contingente dá indícios de, no futuro, tornar-se ou não uma potencial provisão, e, por isso, deve ser divulgado, mas não provisionado. Acrescenta que passivos contingentes também podem derivar de provisões com expectativa de desembolso provável, mas que, no entanto, não tem valor estimado confiável. O CPC 25(R1) ressalta que quando uma provisão e um passivo contingente surgirem de um mesmo conjunto de circunstâncias, a entidade deve divulgar informações suficientes de modo que evidencie a ligação entre eles.

\subsection{A Teoria do Prospecto e o Processo Decisório}

A Teoria do Prospecto aborda as concepções psicológicas acerca do tomador da decisão, que, de modo preponderante, possui maior aversão ao risco em situações de ganhos do que de perdas (Silva, Anjos, Miranda, Souza \& Ranciaro Neto, 2012). Nesse sentido, as finanças comportamentais defendem que as pessoas não são avessas ao risco, mas sim à perda, de modo que preferem evitar a frustração da perda do que sujeitarem-se ao prazer de auferir um ganho equivalente. Portanto, o ser humano é mais propenso em assumir riscos maiores quando está perdendo, embora sejam mais relutantes em assumir os mesmos riscos quando estão ganhando (Araújo \& Silva, 2007).

Sobre o conceito de aversão às perdas, Araújo e Silva (2007) explicam que o medo de perder conduz as pessoas a tomarem decisões irracionais, ignorando dados históricos e probabilidades estatísticas, pois emoções e conceitos equivocados acabam influenciando nas situações de incerteza e risco. Desse modo, a Teoria do Prospecto aponta dois fatores que causam erros de avaliação: (i) a emoção prejudica a racionalidade para tomar decisões e (ii) as pessoas não entendem com discernimento as variáveis com que estão lidando, criando frames ou modelos cognitivos.

Acerca da emoção, Simon (1955) menciona que a atitude humana se baseia em uma racionalidade limitada, pois existem dificuldades para considerar e ponderar todas as variáveis informativas inerentes ao processo decisório, sendo necessária a escolha de apenas algumas destas. Dessa maneira, os indivíduos atribuem valores de preferência aos ganhos e às perdas identificadas, mas não aos resultados finais, e substituem as probabilidades por ponderações subjetivas, isto é, baseadas na cognição (Kahneman \& Tversky, 1984).

Quanto ao frame (modelo cognitivo), a Teoria do Prospecto se refere à possibilidade de indução dos indivíduos a tomar decisões diferenciadas através da manipulação da forma como as informações são apresentadas a eles. Portanto, o frame seria a percepção do tomador de decisões sobre as alternativas disponíveis, os resultados e as probabilidades associadas. Tal percepção está sujeita a interferências causadas por pequenas mudanças na forma de apresentação das alternativas, o que pode influenciar as escolhas dos indivíduos, mesmo que os resultados finais se mantenham os mesmos (Kahneman \& Tversky, 1979, 1984). 
Segundo estes autores, o processo decisório deve ser dividido em duas fases. A fase de estruturação, que consiste em uma análise mental inicial de possíveis prospectos e riscos envolvidos, os quais devem ser simplificados e organizados para o processo de escolha. E a fase de avaliação, que compreende a escolha do prospecto que gere maior valor (Kahneman \& Tversky, 1979). Quando o processo decisório é dividido em duas fases há uma minimização dos erros de preferência.

Kahneman e Riepe (1998) apresentam os principais erros de preferência que afetam o processo decisório (Tabela 1).

Tabela 1 - Principais erros de preferência no processo decisório.

\begin{tabular}{|c|c|}
\hline \multicolumn{2}{|r|}{ Erros de preferência } \\
\hline $\begin{array}{l}\text { Ponderação não linear de proba- } \\
\text { bilidades }\end{array}$ & $\begin{array}{l}\text { Os indivíduos sobrevalorizam baixas probabilidades e subvalorizam altas proba- } \\
\text { bilidades. }\end{array}$ \\
\hline $\begin{array}{l}\text { Valorização de mudanças e não } \\
\text { dos estados finais }\end{array}$ & $\begin{array}{l}\text { O foco é a ocorrência de um ganho ou perda em vez de resultados e condições fi- } \\
\text { nais. }\end{array}$ \\
\hline $\begin{array}{l}\text { Forma e a atratividade da situa- } \\
\text { ção }\end{array}$ & $\begin{array}{l}\text { A forma de apresentação dos ganhos ou perdas afetaria a preferência do indiví- } \\
\text { duo que decide, mesmo diante de resultados finais iguais. }\end{array}$ \\
\hline Assimetria entre ganhos e perdas & $\begin{array}{l}\text { Nas situações de perda os indivíduos tendem requerer um valor equivalente } \\
\text { certo muito maior do que em situações de ganho. }\end{array}$ \\
\hline Concepção restrita & $\begin{array}{l}\text { A tendência é decidir sobre cada fato de forma isolada desconsiderando o estado } \\
\text { final, ao invés de decidir considerando uma combinação de situações. }\end{array}$ \\
\hline
\end{tabular}

Com base nestes erros de preferências, Araújo e Silva (2007) comentam que as finanças comportamentais objetivam identificar e compreender as ilusões cognitivas que levam as pessoas a cometerem erros de avaliação de valores, probabilidades e riscos, ao considerar que as decisões de executivos, administradores, empresários e investidores nem sempre são as mais racionais.

\section{METODOLOGIA}

Neste estudo a abordagem do problema foi qualitativa e quantitativa, por utilizar, respectivamente, a análise documental e testes estatísticos no tratamento dos dados (Richardson, 1999). A amostra estudada é composta por todas as empresas listadas na B3 enquadradas nos segmentos de Construção Civil (CI) e Construção Pesada (PE), totalizando 21 empresas: 18 de Construção Civil e 3 de Construção Pesada. O período de referência dos dados coletados foi o exercício de 2016, a partir do qual se verificou a mudança de comportamento na tendência de valorização das ações das empresas de construção e aparente recuperação econômica (Barra, 2017).

\subsection{Coleta e Análise dos Dados}

Os procedimentos de coleta de dados consistiram na obtenção de dados secundários provenientes do site da BM\&FBOVESPA inserido na página da B3 caracterizando uma pesquisa documental. Os documentos consultados foram as demonstrações contábeis anuais consolidadas e padronizadas encerradas em 31/12/2016, restringindo-se ao Balanço Patrimonial, à Demonstração do Resultado do Período e às Notas Explicativas. O período de análise escolhido justifica-se por ser aquele que marca a valorização repentina das ações das empresas de Construção Civil e Pesada após um período de cotações mínimas históricas, o que gerou dúvidas nos agentes de mercado (Barra, 2017). 
Para a realização da coleta de dados foi utilizado o método de análise documental, por meio do qual foram extraídos (em milhares de reais) os saldos do Ativo, Passivo e Patrimônio Líquido obtidos no Balanço Patrimonial; os valores da Receita Líquida e do Resultado Líquido, obtidos na Demonstração do Resultado do Período; e os valores divulgados sobre Passivos Contingentes, nas Notas Explicativas.

Com relação às informações das Notas Explicativas, foi verificado que os passivos contingentes trabalhistas, cíveis e tributários são os mais recorrentes entre as empresas estudadas, concordando com os achados de Farias (2004), Caetano (2010), Oliveira, Benetti e Varela (2011) e Suave et al. (2013). Apenas quatro empresas divulgaram menor conjunto de contingências passivas: CR2 Empreendimentos Imobiliários S.A. (apenas cível); Even Construtora e Incorporadora S.A., EZ Tec Empreendimentos e Participações S.A. e Rossi Residencial S.A. (apenas cível e trabalhista).

Além disso, apenas a Construtora Tenda S.A. discriminou passivos contingentes de natureza ambiental. Por fim, na MRV Engenharia e Participações S.A.; Rodobens Negócios Imobiliários S.A.; Trisul S.A.; e Construtora Lix da Cunha S.A., os saldos de Passivos Contingentes não foram discriminados por categorias.

Os dados coletados foram organizados em planilhas eletrônicas e receberam tratamento em duas etapas. Primeiramente, com base nos saldos das contas patrimoniais e de resultado originais coletados para cada empresa da amostra, foram calculados indicadores financeiros de liquidez, endividamento e rentabilidade, conforme a Tabela 2:

Tabela 2 - Indicadores financeiros de liquidez, endividamento e rentabilidade.

\begin{tabular}{|c|c|}
\hline Indicador: & Fórmula: \\
\hline Liquidez Geral (LG) & Ativo Total / Passivo Exigível \\
\hline Endividamento Geral (EG) & Passivo Exigível / Ativo Total \\
\hline Margem Líquida (ML) & Resultado Líquido / Receita Líquida \\
\hline Retorno sobre o Ativo (ROA) & Resultado Líquido / Ativo Total \\
\hline Retorno s/ Patrimônio Líquido (ROE) & Resultado Líquido / Patrimônio Líquido \\
\hline
\end{tabular}

Fonte: Adaptado de Assaf Neto (2012).

A segunda etapa consistiu na simulação dos saldos das contas patrimoniais e de resultados da amostra considerando o provisionamento dos passivos contingentes identificados em Notas Explicativas (Equações 1 a 3). Ou seja, realizou-se a reclassificação desses itens quanto à probabilidade de desembolso para sua liquidação, passando da categoria de contingências (itens fora do balanço) para a categoria de provisões (passivos exigíveis).

Passivo Exigível $\mathrm{CP}=$ Passivo Exigível + Passivos Contingentes

Patrimônio Líquido $\mathrm{CP}=$ Patrimônio Líquido - Passivos Contingentes

Resultado do Período $\mathrm{CP}=$ Resultado do Período - Passivos Contingentes

Onde:

$\mathrm{CP}=$ Contingências Passivas divulgadas em Notas Explicativas

Com base nos saldos simulados das contas patrimoniais e de resultado foram calculados os indicadores financeiros apresentados na Tabela 2. Para verificar se o provisionamento dos passivos contingentes tem efeito nos indicadores financeiros foram utilizados testes estatísticos. 
Para aplicação dos testes estatísticos verificou-se a normalidade das variáveis (indicadores econômico-financeiros), por meio do teste de Kolmogorov-Smirnov, o qual indicou que as variáveis não apresentam distribuição normal. Ademais, a análise descritiva do SPSS identificou valores discrepantes no conjunto de dados provenientes das seguintes observações: Construtora Adolpho Lindenberg S.A.; CR2 Empreendimentos Imobiliários S.A.; EZ Tec Empreendimentos e Participações S.A.; PDG Realty S.A. Empreendimentos e Participações; Viver Incorporadora e Construtora S.A.; Azevedo e Travassos S.A.; Construtora Lix da Cunha S.A.; e Mendes Junior Engenharia S.A.. Considerando a ausência de normalidade e por ser uma amostra pequena, com poucas observações, optou-se pelo teste não paramétrico de Wilcoxon (comparação entre amostras pareadas). $\mathrm{O}$ teste de Wilcoxon é adequado quando uma mesma variável é medida antes e depois de um determinado tratamento nos mesmos sujeitos, tendo então duas amostras relacionadas (Maroco, 2007). Em outras palavras, os indicadores econômico-financeiros (LG, EG, ML, ROE e ROA) foram testados em situações distintas (antes e após o efeito do provisionamento das contingências passivas).

Logo, a primeira hipótese testada foi H0: Os passivos contingentes não têm efeito significativo nos indicadores econômico-financeiros de Liquidez Geral (LG), Endividamento Geral (EG), Margem Líquida (ML), Retorno Sobre Ativo (ROA) e Retorno Sobre Patrimônio Líquido (ROE).

Também foi aplicado o teste de McNemar para avaliar contagens ou proporções em duas amostras emparelhadas de variáveis dicotômicas (Maroco, 2007). Então, avaliou-se se houve mudança significativa no número de companhias que apresentam Patrimônio Líquido negativo (variável dicotômica 1 - Reconheceu Patrimônio Líquido Negativo ou 0 - Reconheceu Patrimônio Líquido Positivo) e Prejuízo Contábil no período (variável dicotômica 1 - Reconheceu Prejuízo Contábil ou 0 - Reconheceu Lucro Contábil).

Assim, a segunda hipótese testada foi H0: Não há diferença entre a probabilidade de reconhecer Patrimônio Líquido Negativo e Prejuízo Contábil antes e após o provisionamento dos passivos contingentes.

Os testes estatísticos foram realizados no software IBM SPSS, versão 20.

\section{ANÁLISE DOS RESULTADOS}

Primeiramente apresentam-se os resultados da análise qualitativa do efeito potencial dos passivos contingentes nos indicadores econômico-financeiros das companhias. Em seguida, foram realizados os testes estatísticos.

Pela análise qualitativa foram elencados os montantes de Passivos Contingentes (em milhares de reais) divulgados em Notas Explicativas pelo segmento de Construção Civil e de Construção Pesada; bem como o percentual que tais passivos representam em relação aos saldos Patrimoniais e de Resultado do Período, em 31/12/2016 (Tabela 3).

Tabela 3 - Análise qualitativa dos passivos contingentes divulgados.

\begin{tabular}{l|r|r|r|r|r|r}
\hline Passivos Contingentes & \multicolumn{1}{|c|}{ Cíveis } & Trabalhistas & Tributários & Ambientais ${ }^{\text {a }}$ & Não Discr. $^{\text {b }}$ & Total $^{\prime}$ \\
\hline (Em milhares de reais) & 1.691 .229 & 752.852 & 599.204 & 3.537 & 442.994 & 3.489 .816 \\
\hline \% médio em relação à: & \% Cíveis & \% Trabalhistas & \% Tributários & \% Ambientais & \% Não Discr. & \% Total \\
\hline Ativo & 3,4 & 2,5 & 1 & 0 & 2,2 & 9,1 \\
\hline Passivo & 5,4 & 4,4 & 1,8 & 0 & 3,2 & 14,8 \\
\hline Patrimônio Líquido & 3,6 & 7,6 & 1,6 & 0 & 25,6 & 38,4 \\
\hline Receita Líquida & 1,7 & 4,2 & 5,7 & 0 & $1.533,9$ & $1.545,6$ \\
\hline
\end{tabular}


Silva, T. A, Sanches, L. S. R. \& Igarashi, D. C. C.

\begin{tabular}{l|r|r|r|r|r|r}
\hline Resultado Líquido & $(515,6)$ & $(242,8)$ & $(22,7)$ & 0,4 & 129,4 & $(651,3)$ \\
\hline
\end{tabular}

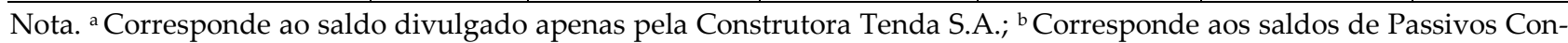
tingentes não discriminados por categorias, divulgados pelas empresas: MRV Engenharia e Participações S.A. (232.544);Rodobens Negócios Imobiliários S.A. (23.360); Trisul S.A. (92.834); e Construtora Lix da Cunha S.A. (94.256).

Fonte: Dados da Pesquisa (2017).

Conjuntamente, as 21 empresas analisadas estão expostas ao risco de realização de $\mathrm{R} \$$ 3.489.816.000,00 em passivos contingentes, distribuídos em Cíveis, Trabalhistas, Tributários, Ambientais e Não Discriminados. Em média, os passivos contingentes divulgados pelas empresas, em 31/12/2016, podem comprometer 9,1\% do Ativo, se considerar a possibilidade de liquidação, e elevar o Passivo em 14,8\%, representando aproximadamente 38,4\% do Patrimônio Líquido das companhias. Embora o Ativo seja o grupo patrimonial com menor comprometimento, deve-se avaliar se uma necessidade de caixa e equivalentes nesta proporção pode ou não comprometer a capacidade financeira das empresas no curto prazo.

Em relação às contas de resultado, verifica-se que, em média, os passivos contingentes divulgados ultrapassam em 1.545,6\% o montante da Receita Líquida auferida no exercício. Também comprometem, em média, 651,3\% do Resultado Líquido, cuja média setorial foi de prejuízo. Em suma, foi observado que a razão entre Receita e as contingências passivas previstas é a mais prejudicada em caso de reconhecimento dos passivos contingentes.

Para a análise qualitativa dos efeitos dos passivos contingentes nos indicadores econômicofinanceiros foi realizado o cálculo da Variação Média do Indicador (em \%). Primeiramente, para cada empresa foi calculada a variação percentual do indicador após o provisionamento dos passivos contingentes, em relação ao mesmo indicador antes do provisionamento. Em seguida, com base nas médias individuais, calculou-se a variação média de cada indicador (Tabela 4).

Tabela 4 - Análise qualitativa dos efeitos dos passivos contingentes nos indicadores financeiros.

\begin{tabular}{|c|c|c|c|c|c|c|}
\hline \multirow{2}{*}{\multicolumn{2}{|c|}{ EMPRESAS }} & \multicolumn{5}{|c|}{ Variação do indicador (em \%) } \\
\hline & & \multirow{2}{*}{$\begin{array}{c}\text { LG } \\
(44,0)\end{array}$} & \multirow{2}{*}{$\begin{array}{c}\text { EG } \\
78,7\end{array}$} & \multirow{2}{*}{$\begin{array}{c}\text { ML } \\
(447,2)\end{array}$} & \multirow{2}{*}{$\begin{array}{c}\text { ROA } \\
(447,2)\end{array}$} & \multirow{2}{*}{$\begin{array}{c}\text { ROE } \\
(2.293,5)\end{array}$} \\
\hline $\mathrm{CI}$ & Construtora Adolpho Lindenberg S.A. & & & & & \\
\hline & CR2 Empreendimentos Imobiliários S.A. & $(11,9)$ & 13,5 & $(7,2)$ & $(7,2)$ & $(9,1)$ \\
\hline & Cyrela Brazil Realty S.A. Empreendimentos e Participações & $(6,9)$ & 7,5 & $(156,0)$ & $(156,0)$ & $(159,3)$ \\
\hline & Direcional Engenharia S.A. & $(9,6)$ & 10,6 & $(17.785,1)$ & $(17.785,1)$ & $(20.749,6)$ \\
\hline & Even Construtora e Incorporadora S.A. & $(2,4)$ & 2,5 & $(161,9)$ & $(161,9)$ & $(163,6)$ \\
\hline & EZ Tec Empreendimentos e Participações S.A. & $(7,3)$ & 7,9 & $(22,8)$ & $(22,8)$ & $(21,3)$ \\
\hline & Gafisa S.A. & $(7,1)$ & 7,6 & $(21,4)$ & $(21,4)$ & $(39,4)$ \\
\hline & Helbor Empreendimentos S.A. & $(3,1)$ & 3,2 & $(108,4)$ & $(108,4)$ & $(121,7)$ \\
\hline & JHSF Participações S.A. & $(7,2)$ & 7,7 & $(77,9)$ & $(77,9)$ & $(95,1)$ \\
\hline & João Fortes Engenharia S.A. & $(4,7)$ & 4,9 & $(22,9)$ & $(22,9)$ & $(54,9)$ \\
\hline & MRV Engenharia e Participações S.A. & $(3,3)$ & 3,4 & $(40,5)$ & $(40,5)$ & $(37,8)$ \\
\hline & PDG Realty S.A. Empreendimentos e Participações. ${ }^{a}$ & $(6,0)$ & 6,4 & $(9,6)$ & $(9,6)$ & 4,9 \\
\hline & Rodobens Negócios Imobiliários S.A. & $(2,8)$ & 2,8 & $(31,0)$ & $(31,0)$ & $(35,2)$ \\
\hline
\end{tabular}




\begin{tabular}{l|l|c|c|c|c|c}
\hline & Rossi Residencial S.A. & $(4,6)$ & 4,8 & $(37,3)$ & $(37,3)$ & $(87,7)$ \\
\hline & Tecnisa S.A. & $(8,4)$ & 9,1 & $(33,6)$ & $(33,6)$ & $(49,4)$ \\
\hline & Construtora Tenda S.A. & $(37,6)$ & 60,3 & $(1.003,9)$ & $(1.003,9)$ & $(1.717,6)$ \\
\hline & Trisul S.A. & $(21,1)$ & 26,7 & $(3.239,1)$ & $(3.239,1)$ & $(3.915,1)$ \\
\hline & Viver Incorporadora e Construtora S.A. ${ }^{b}$ & $(13,2)$ & 15,2 & $(65,2)$ & $(65,2)$ & $(14,2)$ \\
\hline PE & Azevedo e Travassos S.A. & $(3,3)$ & 3,4 & $(13,2)$ & $(13,2)$ & $(941,4)$ \\
\hline PE & Construtora Lix da Cunha S.A. ${ }^{b}$ & $(25,3)$ & 33,9 & $(531,9)$ & $(531,9)$ & $(53,1)$ \\
\hline PE & Mendes Junior Engenharia S.A. ${ }^{\text {b }}$ & $(0,4)$ & 0,4 & $(4,3)$ & $(4,3)$ & $(3,8)$ \\
\hline Variação média do indicador (em \%) & $(11,0)$ & 14,8 & $(1.134,3)$ & $(1.134,3)$ & $(1.455,1)$ \\
\hline
\end{tabular}

Nota. ${ }^{a}$ Nesta empresa a simulação de provisionamento dos Passivos Contingentes causou redução da proporção de Prejuízo do Período em relação ao Patrimônio Líquido Negativo. ${ }^{\text {b }}$ Nestas empresas o provisionamento dos Passivos Contingentes causou aumento da proporção de Prejuízo do Período em relação ao Patrimônio Líquido Negativo.

Fonte: Dados da pesquisa (2017).

Verificou-se que o provisionamento dos passivos contingentes causou, em média, redução de $11 \%$ na LG; aumento de $14,8 \%$ no EG; redução de $1.134,3 \%$ na ML e no ROA; e redução de $1.455,1 \%$ no ROE das companhias estudadas.

As maiores variações ocorridas nos indicadores de LG e EG após o provisionamento das contingências passivas foram identificadas na Construtora Adolpho Lindenberg S.A. (-44\% e 78,37\% respectivamente). Sugere-se que isto ocorreu porque seus passivos contingentes divulgados representaram a maior participação no Passivo Exigível entre todas as empresas da amostra (78,7\%). As maiores variações nos indicadores de ML, ROA e ROE foram verificadas na empresa Direcional Engenharia S.A. (-17.785,1\%, $-17.785,1 \%$ e $-20.749,6 \%$ respectivamente). Esta empresa teve a maior participação dos passivos contingentes em relação ao Resultado do Período (-17.785,1\%). E, a empresa que sofreu as menores variações nos indicadores de LG, EG, ML, ROA e ROE foi a Mendes Junior Engenharia S.A. (-0,4\% e 0,4\%, - 4,3\%, -4,3\% e -3,8\% respectivamente). Os passivos contingentes divulgados por esta empresa representam, entre todas as empresas estudadas, a menor participação em relação ao Passivo Exigível (0,44\%), e ao Resultado do Período (-4,3\%).

A segunda etapa da análise dos dados foram os testes não paramétricos. Com o teste de Wilcoxon foi avaliada a H0: Os passivos contingentes não têm efeito significativo nos indicadores econômico-financeiros de Liquidez Geral (LG), Endividamento Geral (EG), Margem Líquida (ML), Retorno Sobre Ativo (ROA) e Retorno Sobre Patrimônio Líquido (ROE). Para esta análise o teste foi realizado de duas formas: considerando as observações com valores discrepantes identificadas, e em seguida, excluindo-as da análise. Os resultados estão sumarizados na Tabela 5.

Tabela 5 - Teste não paramétrico de Wilcoxon para amostras pareadas.

\begin{tabular}{c|c|c|c|c|c}
\hline Inclui valores discrepantes & LG.CP - LG & EG.CP - EG & ML.CP - ML & ROA.CP - ROA & ROE.CP - ROE \\
\hline$Z$ & $-3,923^{\mathrm{a}}$ & $-4,024^{\mathrm{b}}$ & $-4,015^{\mathrm{a}}$ & $-4,024^{\mathrm{a}}$ & $-3,703^{\mathrm{a}}$ \\
\hline Asymp. Sig. (2-tailed) &, 000 &, 000 &, 000 &, 000 &, 000 \\
\hline Exclui valores discrepantes & LG.CP - LG & EG.CP - EG & ML.CP - ML & ROA.CP - ROA & ROE.CP - ROE \\
\hline Z & $-3,188^{\mathrm{a}}$ & $-3,189^{\mathrm{b}}$ & $-3,182^{\mathrm{a}}$ & $-3,192^{\mathrm{a}}$ & $-3,182^{\mathrm{a}}$ \\
\hline Asymp. Sig. (2-tailed) &, 001 &, 001 &, 001 &, 001 &, 001 \\
\hline
\end{tabular}

Nota. ${ }^{\mathrm{a}}$ baseado em postos positivos; ${ }^{\mathrm{b}}$ baseado em postos negativos. 
Fonte: Dados da pesquisa (2017).

A significância obtida para todas as variáveis foi igual à 0,000 (incluindo valores discrepantes) e 0,001 (excluindo valores discrepantes) (Tabela 5), portanto, pode-se rejeitar a hipótese nula, em um intervalo de confiança de $90 \%$, para a existência de diferença nos indicadores avaliados. Assim, infere-se que o provisionamento dos passivos contingentes tem efeitos significativos nos indicadores de liquidez, endividamento e rentabilidade das companhias analisadas.

Também foi observado que antes do provisionamento dos passivos contingentes apenas 3 companhias (PDG Realty S.A. Empreendimentos e Participações; Viver Incorporadora e Construtora S.A. e Mendes Junior Engenharia S.A.) eram incapazes de liquidar todo o passivo exigível com os ativos totais (LG menor que 1, e EG maior que 1), resultando em Patrimônio Líquido Negativo. Após o provisionamento dos passivos contingentes, uma quarta empresa (Construtora Lix da Cunha S.A.) também apresentou-se com passivo exigível maior que os ativos totais. Além disso, 14 empresas apresentavam Prejuízo Contábil (ML, ROA e ROE negativos) antes do provisionamento dos passivos contingentes, e esse número aumentou para 19 após o provisionamento.

Para comparação da probabilidade de as empresas da amostra reconhecerem Patrimônio Líquido Negativo (LG menor que 1 e EG maior que 1) e Prejuízo Contábil (ML, ROA e ROE negativos) antes e após o provisionamento dos passivos contingentes, foi aplicado o teste não paramétrico de McNemar (Tabela 6).

Tabela 6 - Teste não paramétrico de McNemar para amostras pareadas.

\begin{tabular}{|c|c|c|c|c|c|c|c|c|c|}
\hline \multicolumn{3}{|c|}{$\begin{array}{c}\text { PL_Antes \& } \\
\text { PL_Depois }\end{array}$} & \multicolumn{2}{|c|}{ Test Statistics } & \multicolumn{3}{|c|}{ RE_Antes \& RE_Depois } & \multicolumn{2}{|c|}{ Test Statistics } \\
\hline \multirow{2}{*}{ PL_Antes } & \multicolumn{2}{|c|}{ PL_Depois } & & \multirow{2}{*}{$\begin{array}{c}\text { PL_Antes \& } \\
\text { PL_Depois }\end{array}$} & \multirow[t]{2}{*}{ RE_Antes } & \multicolumn{2}{|c|}{ RE_Depois } & & \multirow{2}{*}{$\begin{array}{l}\text { RE_Antes \& } \\
\text { RE_Depois }\end{array}$} \\
\hline & ,00 & 1,00 & & & & 00 & 1,00 & & \\
\hline 00 & 17 & 1 & $\mathrm{~N}$ & 21 & ,00 & 2 & 5 & $\mathrm{~N}$ & 21 \\
\hline 1,00 & 0 & 3 & $\begin{array}{l}\text { Exact Sig. } \\
\text { (2-tailed) }\end{array}$ & $1,000^{\mathrm{a}}$ & 1,00 & 0 & 14 & $\begin{array}{l}\text { Exact Sig. } \\
\text { (2-tailed) }\end{array}$ &, $063^{\mathrm{a}}$ \\
\hline
\end{tabular}

Os resultados apontam que a significância obtida para comparação entre a frequência de reconhecimento de Patrimônio Líquido Negativo antes e depois do provisionamento dos Passivos Contingentes foi igual a 1,000, portanto, deve-se aceitar a hipótese nula. Logo, a simulação de provisionamento dos Passivos Contingentes não tem efeito de aumento significativo no número de companhias com Patrimônio Líquido Negativo. Tal situação refere-se ao fato de que o montante de Ativo e Passivo Exigível reconhecido das companhias estudadas, para o ano de 2016, não é afetado expressivamente pelo saldo de passivos contingentes divulgados em Notas Explicativas.

Por outro lado, a significância obtida para comparação entre a frequência de reconhecimento de Prejuízo Contábil antes e depois do provisionamento dos Passivos Contingentes foi igual a 0,063. Assim, pode-se rejeitar a hipótese nula, em um intervalo de confiança de $90 \%$. Logo, o provisionamento dos Passivos Contingentes tem efeito de aumento significativo no número de companhias com prejuízo no período. Isso corrobora a observação de que o saldo de Resultado Líquido alcançado pelas empresas em 2016 é mais sensível ao reconhecimento dos Passivos Contingentes, indicando significativa exposição ao risco de perdas. 
Considerando os resultados da análise descritiva e da análise estatística é possível elencar alguns pontos acerca da relevância da informação sobre passivos contingentes ao usuário externo, sob a perspectiva da Teoria do Prospecto.

Segundo a Teoria do Prospecto o tomador de decisões prefere não assumir riscos em situações de ganhos pois tem aversão a incorrer em perdas, optando por abdicar da possibilidade de ganhos maiores. $\mathrm{O}$ fato de passivos contingentes representarem perdas com menor probabilidade de exigirem desembolsos de recursos econômicos para sua liquidação, ou seja, mais prováveis que não aconteçam quando comparados às provisões, não necessariamente significa que serão considerados menos relevantes no processo decisório do usuário. Em outras palavras, a análise minuciosa e objetiva de probabilidades associadas a desfechos futuros nem sempre é o embasamento primordial de uma decisão, pois há casos em que apreensões subjetivas e fatores de cognição são mais valorizados pelos indivíduos.

Nesse sentido, cabe discussão sobre a causa da valorização das ações do setor de construção, ao longo de 2017. Uma possibilidade é o entendimento de que os investidores podem estar mais otimistas em relação ao desempenho dessas companhias para os próximos anos. Tal concepção implicaria duas possibilidades de decisão em relação aos passivos contingentes.

Uma das decisões é a sua atual e baixa probabilidade de gerar desembolso futuro ser ignorada pelo usuário externo que, avesso ao risco, preocupa-se com o potencial reflexo negativo que a realização das contingências passivas pode ocasionar nos indicadores financeiros, além de comprometer expressivamente o Resultado do Período, aspecto evidenciado pelos resultados dos testes estatísticos deste estudo. Neste caso, as decisões tendem a serem mais conservadoras em relação às empresas analisadas. Todavia, o otimismo verificado pode ser decorrente do fato de os investidores confiarem na tendência de queda no contencioso legal das empresas do setor, sobretudo considerando a previsão de que tais empresas deverão se beneficiar da reformulação das regras de distratos negociada pelo governo, que pretende reduzir, no futuro, disputas judiciais em cancelamentos de contratos (Ribeiro, 2017).

A outra decisão é o usuário externo dar preferência à noção atual de baixa probabilidade de desembolso futuro inerente às contingencias passivas, ignorando as probabilidades projetadas evidenciadas pelos resultados que os testes estatísticos apresentam. Nesta hipótese, as decisões em relação à investimentos nessas empresas tendem a ser mais arriscadas. Assim, é possível que os investidores desconsiderem a exposição atual ao risco de realização de passivos contingentes, enfocando apenas as expectativas de retomada dos lançamentos e das vendas dos estoques de imóveis acumulados por estas empresas nos últimos anos, além da tendência de queda da taxa de juros (Ribeiro, 2017), que favorece a recuperação do setor.

Um dos erros de preferência possíveis neste processo seria a assimetria entre a percepção do risco de ganhos e perdas, em que, nas situações de perda, há a tendência em requerer um valor equivalente maior do que em situações de ganho, como preconizado por Kahneman e Riepe (1998). Assim, entende-se que a divulgação de passivos contingentes (perdas com expectativa de desembolso possível) pode afetar a opinião do usuário externo, influenciando decisões favoráveis ou desfavoráveis de investimentos ou concessão de crédito, por exemplo, algo que merece aprofundamento em estudos futuros.

Outro ponto que merece destaque é o fato de as pessoas atribuírem valores de preferência aos ganhos e às perdas identificados, mas não aos resultados finais (Kahneman \& Riepe, 1998). Percebe-se, então, que o usuário supervaloriza informações que indiquem mudanças na situação econômica e financeira da empresa, desconsiderando as condições finais que resultam dos fatores que influenciam em resultados e retornos. Desse modo, seriam fatores relevantes na tomada de decisão as variações desfavoráveis de endividamento, liquidez e rentabilidade (Tabela 3). A adoção desses 
indicadores como base principal para avaliação do desempenho das empresas de construção é importante no cenário atual, principalmente considerando que as perspectivas de recuperação significativa estão presentes em companhias com baixo grau de endividamento (Ribeiro, 2017) e melhores perspectivas de equilíbrio financeiro.

As recentes mudanças econômicas demandam que os investidores reavaliem as métricas de avaliação do desempenho dessas companhias, assumindo critérios essencialmente voltados à situação financeira, ao contrário das tendências passadas, em que o fato de as empresas terem estoques de terrenos era entendido como medida de crescimento dos negócios. Na realidade, isso ocorreu porque nos períodos de crescimento econômico, com excesso de crédito, os imóveis na planta eram negociados em grande volume e, diante disso, as empresas de construção, sobretudo incorporadoras, se endividaram para comprar terrenos e lançar mais empreendimentos. No entanto, com o início da crise econômica, a disponibilidade de crédito cessou, levando a não concretização das vendas esperadas, bem como à devolução dos imóveis pelos clientes que compraram na planta (distratos) (Ribeiro, 2017).

A ocorrência de distratos ainda foi expressiva nos 12 meses encerrados em maio de 2017, o que equivale a 39,4\% das vendas do setor no período (Ribeiro, 2017), o que poderá afetar negativamente o desempenho das companhias nos próximos períodos, sobretudo considerando o nível baixo de receitas e de resultado auferido em 2016. Assim, reafirma-se a importância do conhecimento dos investidores acerca de itens que, mesmo não reconhecidos nas demonstrações contábeis, são responsáveis por mudanças nas condições empresariais, os passivos contingentes. Logo, a Teoria do Prospecto explica que ao rejeitar ambas as hipóteses nulas sabe-se que esses passivos contingentes representam exposição a perdas, de modo que se a decisão for de evitar essas perdas, o tomador de decisão torna-se avesso ao risco, exposto pelas contingências passivas divulgadas.

A relevância de informações sobre passivos contingentes no processo de tomada de decisão também se justifica no conceito de Kahneman e Riepe (1998) sobre ponderação não linear de probabilidades, na qual as pessoas sobrevalorizam baixas probabilidades e subvalorizam as probabilidades elevadas. Nesse sentido, ao decidir sobre a situação de uma companhia, os investidores tenderiam a valorizar mais as perdas possíveis (passivos contingentes divulgados) do que as perdas prováveis (provisões reconhecidas contabilmente). Isso também pode ser explicado pelo fato de as perdas consideradas com expectativa provável de desembolso já terem afetado o resultado das empresas, enquanto as perdas possíveis são potenciais e podem afetar resultados futuros (conforme demonstrado nas Tabelas 2, 3, 4, 5 e 6), sendo relevantes como informações preditivas.

Outro fator relevante da Teoria do Prospecto é o framing, ou seja, a possibilidade de induzir os usuários a tomar decisões diferentes devido ao modo como as informações são apresentadas. Segundo essa concepção, e considerando a atribuição de pesos maiores às informações de perda do que de ganhos, a divulgação de um passivo contingente poderia levar a uma decisão mais desfavorável por parte do usuário em relação à empresa, apesar da baixa probabilidade de ocorrência do evento. Assim, se a empresa entender que a ocorrência da contingência esteja nos limites entre ser remota ou ser possível, a empresa pode optar pela não divulgação (e tratá-la como remota), postergando a noção de perda para o usuário externo.

De modo semelhante, se a empresa entender que a ocorrência de uma contingência esteja nos limites entre ser possível ou ser provável, a empresa pode optar pelo não reconhecimento (e tratá-la como possível), postergando seus efeitos no resultado e, consequentemente, o conhecimento do usuário externo sobre a existência da perda. Assim, há possibilidade de as empresas se utilizarem do caráter subjetivo da normatização do CPC 25(R1) quanto à avaliação da probabilidade de saída de recursos para classificação de passivos para o reconhecimento contábil (como provisões) ou apenas para divulgação (como passivos contingentes). 
Nessas situações, a arbitrariedade da administração tenderia a subavaliar ou superavaliar perdas prováveis ou possíveis para fins de gerenciar os resultados e as prospecções decorrentes deste, ocasionando problemas de seleção adversa e assimetria da informação em relação ao usuário externo. Neste aspecto, o foco de análise é congruente com a perspectiva adotada por Cohen, Darrough, Huang e Zach (2011), Ribeiro, Ribeiro e Weffort (2013) e Ribeiro (2012). Desse modo, se os usuários externos não se atentarem a essas expectativas de perdas possíveis (os passivos contingentes) e remotas (quando passíveis de serem identificadas), suas decisões podem ser mais favoráveis em relação à investimento na empresa, apesar da significativa exposição ao risco de negócios.

\section{CONSIDERAÇÕES FINAIS}

Os principais resultados apontaram que os segmentos de Construção Civil e Construção Pesada estão expostos ao risco de realização de $\mathrm{R} \$ 3.489 .816 .000,00$ em passivos contingentes, capazes de comprometer, em média, 9,1\% do Ativo, elevar o Passivo em 14,8\% e representar 38,4\% do Patrimônio Líquido das companhias (Tabela 3). Tais passivos contingentes ultrapassam o montante da Receita Líquida, atingindo, em média, 1.545,6\% da mesma, e comprometem do Resultado Líquido, cuja média setorial foi prejuízo (Tabela 3). Em decorrência disso, o provisionamento desses passivos contingentes causaria, em média, redução de 11\% na LG; aumento de 14,8\% no EG; redução de $1.134,3 \%$ na ML e no ROA; e redução de $1.455,1 \%$ no ROE das companhias compreendidas na amostra (Tabela 4). Tal variação foi constatada com 90\% de confiança estatística (Tabela 5).

Estatisticamente, a simulação de provisionamento dos Passivos Contingentes não elevou a tendência de as companhias reconhecerem Patrimônio Líquido Negativo (de 3 para 4). Por outro lado, provocou o aumento a probabilidade de reconhecerem Prejuízo no Período (de 14 para 19), fenômeno verificado com $90 \%$ de confiança estatística (Tabela 6), reiterando a observação de que o saldo de Resultado alcançado pelas empresas em 2016 foi pouco expressivo, deixando os acionistas significativamente expostos ao risco de perdas no capital investido.

Mediante a significância atestada das contingências passivas nas medidas de desempenho econômico-financeiro das empresas estudadas, é possível explanar sobre alguns aspectos relacionados à importância da divulgação destes itens, assim como do conhecimento adequado dos mesmos por parte dos usuários externos para tomada de decisão. Tais aspectos podem ser legitimados no âmbito da Teoria do Prospecto. Assim, com base nesta teoria, e em conceitos complementares de Simon (1955) e Kahneman e Riepe (1998), sugere-se alguns pontos relevantes acerca da divulgação de passivos contingentes que merecem aprofundamento em pesquisas futuras:

A possível irracionalidade do tomador de decisões, ao adotar percepções subjetivas em detrimento de informações objetivamente calculadas sobre tendências e probabilidades, demonstra que as informações dos passivos contingentes são importantes aos usuários, apesar de sua menor expectativa de ocorrência.

Se os indivíduos tendem a analisar isoladamente situações de mudança identificadas, desconsiderando resultados finais, então a existência ou não de informações sobre fatos que gerem aumentos ou reduções do patrimônio (contingências) são relevantes na análise dos usuários.

Considerando a assimetria entre a atribuição de importância a informações de ganhos e perdas, no qual a aversão às perdas levaria a preferência por não assumir riscos, os usuários dariam maior importância a informações de perdas do que de ganhos. Sendo assim, a divulgação de passivos contingentes exerceria influência na análise do usuário, podendo ser determinante para uma decisão favorável ou desfavorável em relação à empresa.

Uma vez que há ponderação não linear de probabilidades, passivos contingentes podem ser mais valorizados por sua menor probabilidade de ocorrência do que passivos com maior probabilidade (aqueles que estão reconhecidos contabilmente). 
O gerenciamento da divulgação das informações sobre passivos contingentes pode influenciar uma decisão favorável ou desfavorável do usuário. Destarte, a discricionariedade da administração pode alterar o momento em que perdas são reconhecidas, dependendo do julgamento acerca da probabilidade de saída de recursos econômicos para a liquidação, o que pode caracterizar práticas de gerenciamento de resultados.

Tais aspectos corroboram a afirmação de que todos os elementos que acarretem, mesmo que de forma incerta, mudanças na situação econômico-financeira das empresas devem ser considerados pelo usuário externo, mesmo não sendo reconhecidos nas demonstrações contábeis.

Desse modo, há indícios para sugerir que as perdas reconhecidas contabilmente (as Provisões) são relevantes para reportar a situação passada das empresas de Construção Civil e Construção Pesada, e já estão representadas nas Demonstrações Financeiras até o encerramento do exercício de 2016. Todavia, é relevante que os potenciais investidores avaliem os montantes de saldos que estão fora das demonstrações contábeis (os Passivos Contingentes), uma vez que estes são relevantes para reportar expectativas de situações futuras ou prospectivas dessas organizações, e, neste caso, apesar da aparente recuperação financeira e do expressivo crescimento no valor de mercado dessas companhias no início de 2017, existe significativa exposição ao risco de assunção de obrigações cíveis, trabalhistas e tributárias.

Em suma, a análise dos usuários externos torna-se mais eficaz caso considere os efeitos de perdas possíveis e até mesmo remotas (quando passíveis de identificação) no cálculo dos indicadores econômico-financeiros das empresas, pois essas informações refletem o nível de exposição ao risco de investimento e concessão de crédito, sobretudo, pelo fato de estes passivos contingentes (se provisionados) poderem provocar a quebra de covenants contratuais, em decorrência da redução significativa dos índices de liquidez e rentabilidade, e pelo aumento expressivo dos índices de endividamento (Tabela 4 ).

Sendo assim, entende-se que apesar de não reconhecidos, os passivos contingentes podem ser tão relevantes quanto os demais passivos na decisão do usuário, pois são evidências de exposição ao risco. Assim, conclui-se que a Teoria do Prospecto reforça a ideia de utilidade da informação contábil aos usuários externos quando da divulgação de passivos contingentes, ou seja, esta colabora com o processo decisório, porque é uma informação útil e preditiva.

\section{REFERÊNCIAS}

Amorim, L. (2015). Construção civil vive crise sem precedentes no Brasil. Recuperado em 20 Junho, 2017, de http://exame.abril.com.br/revista-exame/a-crise-e-a-crise-da-construcao/.

Araujo, D. R. De \& Silva, C. A. T. (2007). Aversão à perda nas decisões de risco. REPEC - Revista de Educação e Pesquisa em Contabilidade, Brasília, 1 (3), 45-62. Recuperado em 20. abr. 2017 de http://www.repec.org.br/index.php/repec/article/view/15/17.

Assaf Neto, A. (2012). Estrutura e análise de balanços: um enfoque econômico-financeiro. (10a. ed.). São Paulo: Atlas.

Baraldi, P. (2012). IFRS: Contabilidade criativa e fraudes. Rio de Janeiro: Elsevier.

Barberis, N., \& Thaler, R. (2003). A survey of behavioral finance. Handbook of the Economics of Finance, 1, 1053-1128. 
Barra, P. (2017). De "quebradas" em 2016 para altas de até 300\% em 2017: dá para confiar no rali das construtoras? Recuperado em 20 Abril, 2017, de http://www.infomoney.com.br/mercados/acoes-e-indices/noticia/6030624/quebradas-2016-para-altas-ate-300-2017-para-confiar-rali

Caetano, T. P., Silva, T. B., Biesdorf, S. \& Leal, E. A. (2010). Evidenciação do Passivo Contingencial nas Demonstrações Contábeis: Um estudo nas Empresas de Papel e Celulose. Anais do Congresso USP de Controladoria e Contabilidade, FEA/USP, São Paulo, 10.

Cardoso, R. L., Riccio, E. \& Lopes, A. B. (2008). O processo decisório em um ambiente de informação contábil: um estudo usando a teoria dos prospectos. Revista de Administração e Contabilidade da Unisinos, 5 (2), 85-95.

Castelo, A. M. (2017). Otimismo cresce na construção, mas retomada ainda vai demorar. Recuperado em 20 Junho, 2017 de http://www.infomoney.com.br/mercados/na-real/noticia/6185352/otimismo-cresce-construcao-mas-retomada-ainda-vai-demorar

Cataldo, B. (2016). Construção civil alinha propostas para retomada da economia. Recuperado em 20 Junho, 2017, de http://g1.globo.com/economia/blog/beth-cataldo/post/construcao-civil-alinha-propostas-para-retomada-da-economia.html.

Cohen, D., Darrough, M., Huang, R. \& Zach, T. (2011). Warranty Reserve: Contingent Liability, Information Signal, or Earnings Management Tool? Accounting Review, 86 (2), 569 - 604.

Comitê De Pronunciamentos Contábeis. CPC 25 (R1) - Provisões, Ativos Contingentes e Passivos Contingente, 2009. Recuperado em 20. abr. 2017 de http://www.cpc.org.br/CPC/DocumentosEmitidos/Pronunciamentos/Pronunciamento?Id=56.

Comissão de Valores Mobiliários (2005). Deliberação CVM n ${ }^{\circ} 489$ de 3 de Outubro de 2005. Recuperado em 20. abr. 2017 de http://www.cvm.gov.br/export/sites/cvm/legislacao/deli/anexos/0400/deli489.pdf.

Comissão de Valores Mobiliários (2009). Deliberação CVM no 594, de 15 de Setembro de 2009. Recuperado em 20. abr. 2017 de http://www.cvm.gov.br/export/sites/cvm/legislacao/deli/anexos/0500/deli594.pdf.

Cooper, D. R. \& Schindler, P. S. (2003). Métodos de pesquisa em administração. (7a. ed.) Porto Alegre: Bookman.

Currie, E. \& Velandia, A. (2002). Risk Management of Contingent Liabilities Within a Sovereign AssetLiability Framework.

Ernst \& Young Terco (2011). Contingências trabalhistas na construção crescem 232\% em 4 anos. Tax View, (Edição Especial), 36, 3 - 13.

Farias, M. R. S. (2004). Divulgação do passivo: um enfoque sobre o passivo contingente no setor químico e petroquímico brasileiro. Dissertação de Mestrado em Controladoria e Contabilidade. Programa de pós-graduação em Ciências Contábeis, Faculdade de Economia, Administração e Contabilidade da Universidade de São Paulo, São Paulo, SP. 
Fonteles, I. V., Nascimento, C. P. S., Ponte, V. M. R. \& Rebouças, S. M. D. P. (2012). Determinantes da evidenciação de provisões e contingências por companhias listadas na BM\&FBOVESPA. Anais do Congresso USP de Controladoria e Contabilidade, FEA/USP São Paulo, 12.

Kahneman, D. \& Riepe, M.W. (1998). Aspects of investor psychology. The Journal of Portfolio Managemen, $24(4), 52-65$.

Kahneman, D. \& Tversky, A. (1979). Prospect theory: an analysis of decision under risk. Econometrica, Chicago, 47(2), $263-291$.

Kahneman, D. \& Tversky, A. (1984). Choices, values e frames. American Psychologist, 39 (4), 341 - 350.

Kennedy, J., Mitchell, T. \& Sefcik, S. E. (1998). Disclosure of Contingent Environmental Liabilities: Some Unintended Consequences? Journal of Accounting Research, 36 (2), 257 - 277.

Mackenzie, B., Coetsee, D., Njikizana, T., Chamboko, R., Colyvas, B. \& Hanekom, B. (2013). IFRS 2012: Interpretação e Aplicação (1a. ed.). Porto Alegre: Bookman.

Maroco, J. (2007). Análise Estatística: com a utilização do SPSS. (3a. ed.) Lisboa: Silabo.

Martins E., Iudícibus, S. de, Gelbcke, E. R. \& Santos, A. dos (2013). Manual de Contabilidade Societária: aplicável a todas as sociedades (2a. ed). São Paulo: Atlas.

Ministério Público Do Trabalho (2014). Programa Nacional de Acompanhamento de obras na construção civil pesada. Recuperado em 20. abr. 2017 de http://portal.mpt.gov.br/wps/wcm/connect/23620f80467f7fa993b9b768f02cfb99/copa.pdf?MOD=AJPERES\&CACHEID=23620f80467f7fa993b9b768f02cfb99.

Oliveira, A. F., Benetti, J. E. \& Varela, P. S. (2011). Disclosure das provisões e dos passivos e ativos contingentes: um estudo em empresas listadas na BM\&FBovespa. Anais do Congresso da Associação Nacional dos Programas de Pós-Graduação em Ciências Contábeis (ANPCONT), Anpcont, Vitória, 5.

Oliveira, J. da S. (2007). Relato Financeiro Sobre Provisões, Passivos Contingentes e Ativos contingentes: o caso português. Contabilidade e Gestão, (4) 19 - 68.

Ribeiro, A. De C. (2012). Provisões, Contingências e Normas Contábeis: Um Estudo de Gerenciamento de Resultados com Contencioso legal no Brasil. Dissertação de Mestrado em Controladoria e Contabilidade, Programa de pós-graduação em Controladoria e Contabilidade, Faculdade de Economia, Administração e Contabilidade da Universidade de São Paulo, Ribeirão Preto, SP.

Ribeiro, A. De C., Ribeiro, M. De S. \& Weffort, E. F. J. (2013). Provisões, Contingências e o Pronunciamento CPC 25: As Percepções dos Protagonistas envolvidos. Revista Universo Contábil, Blumenau, 9 (3), $38-54$. 
Ribeiro, A. P. (2017). Com queda de juros, ações de construção voltam a se valorizar. São Paulo. Recuperado em 30. Out. 2017, de https://oglobo.globo.com/economia/com-queda-de-jurosacoes-de-construcao-voltam-se-valorizar-21649287

Richardson, R. J. (1999). Pesquisa Social: Métodos e técnicas. (3a. ed.). São Paulo: Atlas.

Serviço Brasileiro de Apoio às Micro e Pequenas Empresas (2016). Cenários Prospectivos: O setor de construção no Brasil, de 2016 a 2018.

Silva, D. J. C. Da, Anjos, L. C. M. Dos, Miranda, L. C., Souza, L. E. S. D. \& Ranciaro Neto, A. (2012). Revisitando a Prospect Theory: seriam os contadores mais racionais? Contexto. Porto Alegre. 12 (21), $29-40$.

Simon, H. A. (1955). A Behavioral Model of Rational Choice. In: Models of Man: Social and Rational. The Quarterly Journal of Economics. 69 (1), 99 - 118.

Suave, R., Codesso, M. M., Pinto, H. De M., Vicente, E F. R. \& Lunkes, R. J. (2013). Divulgação de Passivos Contingentes nas empresas mais líquidas da BM\&Fbovespa. Revista da UNIFEBE, 1 (11), $1-17$.

Tribunal Superior do Trabalho (2014). AEPS 2013 - Seção IV - Acidentes do Trabalho - Tabelas. Recuperado em 20 Junho, 2017, de http://www.previdencia.gov.br/dados-abertos/aeps-2013anuario-estatistico-da-previdencia-social-2013/aeps-2013-secao-iv-acidentes-do-trabalho/aeps2013-secao-iv-acidentes-do-trabalho-tabelas/.

Zeelenberg, M., Van Dijk, W. W., Manstead, A. S., \& Pligt, J. Van der (2000). On bad decisions and disconfirmed expectancies: The psychology of regret and disappointment. Cognition \& Emotion, 14(4), 521-541. 